Животноводство и кормопроизводство 2020 T. 103 № 3/Animal Husbandry and Fodder Production 2020 Vol. 103 Is. 3

Технология производства, качество продукции и экономика в мясном скотоводстве 145

УДК 636.92:577.17:591.11

DOI: $10.33284 / 2658-3135-103-3-145$ Влияние ультрадисперсных частиц серебра на морфобиохимические показатели крови
животных при тепловом стрессе

\author{
Е.А. Аэсмулдинов, М.Г. Титов, М.А. Кизаев, Т.Н. Холодилина \\ Федеральный научный центр биологических систем и агротехнологий Российской академии наук (2. Оренбург)
}

\begin{abstract}
Аннотация. Тепловой стресс оказывает негативное влияние на здоровье и продуктивность животных, вызывая огромные экономические потери. Альтернативой существующим подходам, позволяющим минимизировать отрицательный эффект стресс-факторов, может стать применение ультрадисперсных частиц (УДЧ) металлов, в частности серебра. Цель исследований заключалась в изучении дозозависимого эффекта влияния УДЧ серебра на морфобиохимический состав крови животных в условиях высоких температур. Эксперимент проводился на самцах кроликов породы «Великан» пятимесячного возраста в стандартных условиях вивария. Были сформированы три группы: контрольная и две опытных. Кроликов всех групп подвергли тепловому воздействию (экспозиция -3 часа при $\mathrm{t}+42{ }^{\circ} \mathrm{C}$ и влажности воздуха $75 \%$ ). Животным опытных групп ежедневно, за семь суток до начала теплового воздействия, внутримышечно вводилась суспензия УдЧ серебра в католите в дозах: I группа - 0,01, II - 0,05 мг/кг живой массы.

Коррекция теплового стресса суспензией УДЧ серебра в католите привела к снижению некоторых показателей крови. В частности, гематокрит, гемоглобин, лейкоциты и тромбоциты имели тенденцию к снижению по сравнению с контрольной группой с выраженностью эффекта при низкой дозе 0,01 мг/кг живой массы. Активность трансфераз сыворотки крови: гамма-глутамилтрансферазы (ГГТ), аспартатаминотрансферазы (АСТ) и аланинаминотрансферазы (АЛТ) сохраняла высокое значение при отсутствии коррекции теплового стресса (контрольная группа) и значимо снижалась $(\mathrm{P} \leq 0,01)$ при применении низкой дозы (І опытная группа).

Таким образом, использование суспензии УдЧ серебра в католите в дозе 0,01 мг/кг живой массы способствует улучшению защитных свойств организма и обладает протективным эффектом в отношении теплового стресса.
\end{abstract}

Ключевые слова: кролики, УДЧ серебра, кровь, сыворотка, гамма-глутамилтрансфераза, аланинаминотрансфераза, аспартатаминотрансфераза, тепловой стресс.

UDC 636.92:577.17:591.11

\title{
Influence of ultrafine silver particles on morphobiochemical parameters of animals under heat stress
}

\author{
Elemes A Azhmuldinov, Maxim G Titov, Mikhail A Kizaev, Tatyana N Kholodilina \\ Federal Research Centre of Biological Systems and Agricultural Technologies of Russian Academy of Sciences (Orenburg, Russia)
}

Summary. Heat stress has a negative impact on health and productivity of animals, causing huge economic losses. An alternative to the existing approaches to minimize the negative effect of stress factors can be the use of ultrafine particles (UFP) of metals, in particular silver. The aim of the research was to study the dosedependent effect of silver UFPs on morphobiochemical composition of blood of animals at high temperatures. The experiment was carried out on 5-month male rabbits of the Giant breed under standard vivarium conditions. Three groups were formed: control and two experimental. Rabbits of all groups were exposed to heat (exposure for three hours at $\mathrm{t}+42{ }^{\circ} \mathrm{C}$ and air humidity $75 \%$ ). The animals of the experimental groups were injected intramuscularly with a suspension of silver UFP in catholyte daily, seven days before the start of heat exposure, in doses: Group I - 0.01, II - $0.05 \mathrm{mg} / \mathrm{kg}$ of live weight.

Correction of heat stress with a suspension of silver UFP in catholyte led to a decrease in some blood parameters. In particular, hematocrit, hemoglobin, leukocytes and platelets tended to decrease compared to the control 


\section{6 Технология производства, качество продукции и экономика в мясном скотоводстве}

group with the severity of the effect at a low dose of $0.01 \mathrm{mg} / \mathrm{kg}$ body weight. The activity of serum transferases: gamma-glutamyl transferase (GGT), aspartate aminotransferase (AST), and alanine aminotransferase (ALT) remained high in the absence of heat stress correction (control group) and significantly $(\mathrm{P} \leq 0.01)$ decreased with the use of a low dose (Group I).

Thus, the use of a suspension of silver UFP in catholyte at a dose of $0.01 \mathrm{mg} / \mathrm{kg}$ of live weight improves the protective properties of body and has a protective effect against heat stress.

Key words: rabbits, silver UFP, blood, serum, gamma-glutamyltransferase, alanine aminotransferase, aspartate aminotransferase, heat stress.

\section{Введение.}

Стрессовый фактор окружающей среды, такой как тепловой стресс (ТC), является одной из основных проблем, которые оказывают негативное влияние на физиологию, поведение, здоровье и продуктивность животных, вызывая огромные экономические потери. ТС может отрицательно влиять на биологические макромолекулы, такие как белки, липиды, углеводы и ДНК путём образования и накопления активных форм кислорода (АФК) и свободных радикалов в клетках при выполнении своих обычных метаболических функций, что приводит к повреждению клеток и появлению патологических симптомов (Меерсон Ф.З., 1981; Ажмулдинов Е.А. и др., 2018).

Было разработано несколько подходов, позволяющих избежать отрицательного воздействия технологических стрессов на животных, включая использование растительных кормовых добавок, минералов и витаминов. Ряд микроэлементов эффективно используется для снижения и предотвращения негативного воздействия стресса у различных видов животных (Меерсон Ф.З., 1981). Серебро - микроэлемент, необходимый для поддержания здоровья и активной жизнедеятельности живого организма. Оно способствует усилению работы антиоксидантных ферментов и помогает контролировать уровень перекисей липидов и водорода, которые образуются в результате метаболической активности (Abou El-Nour KMM et al., 2010; Saini P et al., 2016). Серебро жизненно важно для деятельности иммунной системы, особенно при воздействиях технологических стресс-факторов, а биодоступность связана с его физической формой. Серебро в ультрадисперсной форме (УДЧ) демонстрирует инновационные свойства, такие как высокая поверхностная активность, каталитическая эффективность, сильная адсорбирующая способность (Al-Sagheer AA et al., 2017; Ognik K et al., 2016, Ажмулдинов Е.А. и др., 2020; Титов М.Г. и др., 2020).

В настоящее время УДЧ широко используются в животноводстве и птицеводстве как альтернативные источники микроэлементов, что улучшает обмен веществ, иммунитет и продуктивность (Ognik K et al., 2016; Al-Sagheer AA et al., 2017; Sizova E et al., 2020).

В частности, УдЧ серебра благодаря антибактериальным и противогрибковым свойствам стали применять в животноводстве в качестве мощного дезинфицирующего средства (Aklakur M et al., 2016; Ажмулдинов Е.А. и др., 2019).

Несмотря на обилие информации об использовании различных источников серебра в животноводстве, о влиянии их на организм при различных стрессах известно недостаточно для широкого использования в животноводстве.

\section{Цель исследования.}

Изучить особенности влияния различных доз УДЧ серебра на морфобиохимический состав крови животных в условиях высоких температур.

\section{Материалы и методы исследования.}

Объект исследования. Кролики породы «Великан» пятимесячного возраста.

Обслуживание животных и экспериментальные исследования были выполнены в соответствии с инструкциями и рекомендациями Russian Regulations, 1987 (Order No.755 on 12.08.1977 the USSR Ministry of Health) and «The Guide for Care and Use of Laboratory Animals (National Academy Press Washington, D.C. 1996)». При выполнении исследований были предприняты усилия, чтобы свести к минимуму страдания животных и уменьшения количества используемых образцов. 
Схема эксперимента. Исследования проводили на кроликах-самцах пятимесячного возраста в стандартных условиях вивария. После 14-суточного подготовительного периода их разделили на три группы: контрольную и две опытные. Кролики всех групп были подвергнуты воздействию высоких температур. Тепловой стресс создавали с помощью тепловой пушки Зубр Мастер компакт ЗТП-М1-3000 с контролем температуры в индивидуальной камере. Продолжительность воздействия составляла 3 часа при температуре $+42{ }^{\circ} \mathrm{C}$ и влажности $75 \%$, данные регистрировались гигрометром психрометрическим ВИТ-1. Животным опытных групп ежедневно, в течение семи суток до начала теплового воздействия внутримышечно вводилась суспензия, состоящая из католита (pH - 9,5; редокс-потенциал $\mathrm{Eh}=-450$ мВ (Дворников В.M., 2004) с УДЧ серебра в дозах: I группа - 0,01 и II - 0,05 мг/кг живой массы. Забор крови проводили из краевой вены уха в конце эксперимента.

УДЧ серебра состояли по химическому и фазовому составу из: 99,99 \% металлического серебра, адсорбированных газов до $0,01 \%-\mathrm{CH}_{4}, \mathrm{CO}_{2}, \mathrm{Ar}, \mathrm{N}_{2}$, метод получения - электрический взрыв в атмосфере аргона, удельная поверхность $-\mathrm{S}_{\mathrm{vд}}=6,5 \mathrm{~m}^{2} / \Gamma$. Для приготовления инъекционной суспензии УДЧ серебра смешивали с католитом, полученным в аппарате AkvaLife, и подвергали диспергированию в ультразвуковом диспергаторе УЗДН-2Т в режиме 0,5 А, 44 кГц.

Оборудование и технические средства. Морфологические и биохимические показатели крови определяли в центре «Нанотехнологии в сельском хозяйстве» ФНЦ БСТ РАН с использованием автоматического гематологического анализатора URIT-2900 Vet Plus («URIT Medial Electronic Co., Ltd», Китай) и автоматического анализатора CS-T240 («DIRUI Industrial Co., Ltd», Китай) с использованием коммерческих наборов для ветеринарии ДиаВетТест (Россия) и Randox Laboratories Limited (United Kingdom).

Статистическая обработка. Основной материал, полученный в исследованиях, обработан с использованием с помощью офисного программного комплекса «Microsoft Office» с применением программы «Excel» («Microsoft», США), достоверность определяли при помощи критерия Стьюдента.

\section{Результаты исследования.}

Одним из основных показателей гомеостаза организма является кровь, где отражены основные качественные и количественные компенсаторные реакции при действии стрессогенных факторов.

Внутримышечное введение УдЧ серебра оказало определённое влияние на показатели крови кроликов (табл. 1).

Таблица 1. Морфологический состав крови животных Table 1. Morphological composition of animal blood

\begin{tabular}{|c|c|c|c|}
\hline \multirow[b]{2}{*}{ Показатель/Indicator } & \multicolumn{3}{|c|}{ Группа/ Group } \\
\hline & $\begin{array}{c}\text { контрольная/ } \\
\text { control }\end{array}$ & I & II \\
\hline Эритроциты, $10^{12}$ к/л/Erythrocytes, $10^{12} \mathrm{k} / \mathrm{l}$ & $4,64 \pm 0,427$ & $3,69 \pm 0,453^{*}$ & $4,07 \pm 0,417$ \\
\hline Лейкоциты, $10^{9} \mathrm{\kappa} / л /$ Leukocytes, $10^{9} \mathrm{k} / \mathrm{l}$ & $10,6 \pm 0,37$ & $7,6 \pm 0,41$ & $8,0 \pm 0,45$ \\
\hline Гемоглобин, г/л/Hemoglobin, g/l & $121,0 \pm 0,41$ & $95,0 \pm 0,40^{*}$ & $101,0 \pm 0,37 *$ \\
\hline Лимфоциты, $10^{9} \mathrm{\kappa} / л /$ Lymphocytes, $10^{9} \mathrm{k} / \mathrm{l}$ & $4,3 \pm 0,51$ & $2,4 \pm 0,50$ & $2,3 \pm 0,47$ \\
\hline Лимфоциты, \% / Lymphocytes, \% & $29,7 \pm 0,36$ & $42,2 \pm 0,35$ & $30,6 \pm 0,32$ \\
\hline Гранулоциты, $10^{9}$ к/л / Granulocytes, $10^{9} \mathrm{k} / \mathrm{l}$ & $4,9 \pm 0,51$ & $4,9 \pm 0,53$ & $4,9 \pm 0,46$ \\
\hline Гранулоциты, \% / Granulocytes, \% & $62,1 \pm 0,35$ & $44,6 \pm 0,37$ & $60,7 \pm 0,31$ \\
\hline Гематокрит, \% / Hematocrit, \% & $33,9 \pm 0,42$ & $26,5 \pm 0,53^{*}$ & $27,1 \pm 0,57^{*}$ \\
\hline Тромбоциты, $10^{9} \mathrm{\kappa} / л /$ Platelets, $10^{9} \mathrm{k} / \mathrm{l}$ & $222,0 \pm 0,38$ & $174,0 \pm 0,49 *$ & $178,0 \pm 0,44^{*}$ \\
\hline
\end{tabular}

Примечание: *-P $\leq 0,05$

Note: ${ }^{*}-\mathrm{P} \leq 0.05$ 
В организме в ответ на стресс-воздействие сразу же происходило повышение уровня эритроцитов, так называемая стресс-полицителия, при которой из кровяных депо в кровяное русло выбрасываются эритроциты. В контрольной группе отмечено большее эритроцитов на $25,7 \%$ $(\mathrm{P} \leq 0,05)$ и $14,0 \%(\mathrm{P}<0,05)$ по сравнению с I и II группами соответственно.

На фоне коррекции теплового стресса (I и II группы) величина гематокрита была на 7,4 и $6,8 \%(\mathrm{P} \leq 0,05)$ ниже по сравнению с контрольной группой.

У животных I и II опытных групп снижалось количество: гемоглобина - на $21,5 \%$ (P $\leq 0,05)$ и $16,5 \%$ ( $\mathrm{P} \leq 0,05)$, тромбоцитов - на $21,6 \%(\mathrm{P} \leq 0,05)$ и $19,8 \%(\mathrm{P} \leq 0,05)$ соответственно по сравнению с контрольными аналогами. Лейкоцитоз был характерен для контрольных кроликов, который на 39,5 и $32,5 \%(\mathrm{P} \leq 0,05)$ превышал значения у сверстников I и II опытных групп.

Таблица 2. Некоторые биохимические показатели сыворотки крови подопытных животных Table 2. Some biochemical parameters of blood serum of experimental animals

\begin{tabular}{|c|c|c|c|}
\hline \multirow[b]{2}{*}{ Показатель/Indicator } & \multicolumn{3}{|c|}{ Группа/ Group } \\
\hline & $\begin{array}{c}\text { Контрольная/ } \\
\text { control }\end{array}$ & I & II \\
\hline Общий белок, г/л/Total protein, $g / l$ & $75,9 \pm 4,31$ & $72,2 \pm 5,28$ & $72,8 \pm 5,40$ \\
\hline Альбумины, г/л / Albumin, $g / l$ & $48,0 \pm 3,25$ & $44,0 \pm 3,51$ & $47,0 \pm 4,35$ \\
\hline Билирубин общ., мкмоль/л / Total bilirubin, $\mu \mathrm{mol} / \mathrm{l}$ & $0,76 \pm 0,021$ & $0,50 \pm 0,05$ & $0,59 \pm 0,032$ \\
\hline Холестерин, ммоль/л / Cholesterol, $\mathrm{mmol} / \mathrm{l}$ & $1,28 \pm 0,170$ & $0,92 \pm 0,05$ & $0,98 \pm 0,023$ \\
\hline Триглицериды, ммоль/л / Triglycerides, mmol/l & $1,96 \pm 0,543$ & $1,62 \pm 0,64$ & $1,73 \pm 0,604$ \\
\hline Глюкоза, ммоль/л / Glucose, $\mathrm{mmol} / \mathrm{l}$ & $9,4 \pm 0,20$ & $8,6 \pm 0,13$ & $9,3 \pm 0,17$ \\
\hline $\mathrm{Fe}$, мкмоль/л / Fe, $\mu \mathrm{mol} / \mathrm{l}$ & $42,5 \pm 5,15$ & $21,8 \pm 3,04$ & $27,0 \pm 3,73$ \\
\hline Р, ммоль/л / $P, \mathrm{mmol} / \mathrm{l}$ & $5,3 \pm 0,71$ & $4,1 \pm 0,55$ & $4,8 \pm 0,67$ \\
\hline
\end{tabular}

На основании биохимического анализа (табл. 2) было установлено, что отсутствие коррекции стресс-реакции (контрольная группа) приводит к увеличению общего белка на $5,1 \%(\mathrm{P} \leq 0,05)$ и 4,3\% $(\mathrm{P} \leq 0,05)$, альбуминов - на $9,1 \%(\mathrm{P} \leq 0,05)$ и $2,1 \%$, билирубина - на $52 \%(\mathrm{P} \leq 0,05)$ и $28,8 \%(\mathrm{P} \leq 0,05)$; холестерина - на 39,1 и $30,6 \%$, триглицеридов - на $21,0 \%(\mathrm{P} \leq 0,05)$ и $13,3 \%(\mathrm{P} \leq 0,05)$ соответственно по сравнению с I и II группами. Соответственно, введение суспензии УДЧ серебра в католите (I и II группы) приводило к снижению указанных показателей. Количество глюкозы в I и II группах было ниже, чем у контрольных сверстников на 8,5 и $1,1 \%$ соответственно.

Влияние стресс-фактора сопровождалось повышением активности трансфераз, со снижением при введении суспензии УДЧ серебра в католите (табл. 3).

Таблица 3. Динамика активности гама-глутамил и аминотрансфераз сыворотки крови животных Table 3. Dynamics of the activity of gamma-glutamyl and aminotransferases in the blood serum of animals

\begin{tabular}{|l|c|c|c|}
\hline \multirow{2}{*}{ Показатель/Indicator } & \multicolumn{3}{|c|}{ Группа } \\
\cline { 2 - 4 } & контрольная/ control & I & II \\
\hline ГГТ, ЕД/Л / GGT, U/l & $9,0 \pm 0,22$ & $6,0 \pm 0,63$ & $7,0 \pm 0,52$ \\
АСТ, ЕД/Л / $A S T, U / l$ & $34,7 \pm 2,07$ & $25,6 \pm 1,95^{* *}$ & $29,5 \pm 1,64$ \\
АЛТ, ЕД/л/ $A L T, U / l$ & $63,7 \pm 1,38$ & $43,8 \pm 1,48^{* *}$ & $49,7 \pm 1,50$ \\
\hline
\end{tabular}

Примечание: **-P $\leq 0,01$

Note: ** $-\mathrm{P} \leq 0,01$

Условия гипертермии без коррекции стресс-реакции (контрольная группа) вызывали повышение активности ферментных систем сыворотки крови. Так, активность ГГТ увеличивалась на 50,0 и $28,6 \%$, АСТ - на $35,5(\mathrm{P} \leq 0,01)$ и $17,6 \%(\mathrm{P} \leq 0,01)$, а АЛТ - на 45,4 и $28,2 \%(\mathrm{P} \leq 0,01)$ соответственно по сравнению со сверстниками из I и II групп. 


\section{Обсуждение полученных результатов.}

Гематологические показатели, зависящие от возраста, питания, стресса, температуры, беременности, мышечной активности и патологических состояний, предоставляют важную информацию о состоянии здоровья животного при различных физиологических состояниях и факторах воздействия (Abd FG, 2014; Fathi M et al., 2017, Ажмулдинов Е.А. и др., 2018).

При использовании суспензии с УДЧ серебра в дозах 0,01 и 0,05 мг/кг живой массы был установлен антистрессовый эффект, что способствовало снижению негативного воздействия высоких температур на физиологические показатели животных (Fondevila M, 2010; Kulak E et al., 2018).

Между тем функциональные возможности эритроцитов во многом определяются активностью их антиоксидантных систем. Raheem HQ (2018) обнаружил повышение уровней эритроцитов, тромбоцитов и гематокрита у животных, подверженных стрессу, что было подтверждено нашими исследованиями: увеличение эритроцитов составило 25,7 и 14,0 \% у кроликов, получивших тепловой стресс. Нarhan OM и Нusain RM (2014) отметили, что инъекции УДЧ серебра, вводимые внутривенно, приводят к изменениям показателей эритроцитов и тромбоцитов, что связано с усиленным иммунным ответом. Тогда как Marai IFM с коллегами (2007) связывают увеличение количества тромбоцитов с негативным воздействием высоких температур на кроветворные органы. У стрессированных кроликов уровень лейкоцитов и тромбоцитов был повышен.

Результаты исследования показали, что введение УдЧ серебра в дозировках 0,01 и 0,05 мг/кг живой массы приводило к стабилизации гематокрита, к значениям, близкими к норме, что свидетельствует об улучшении состояния организма животного.

Общая тенденция снижения триглицеридов, холестерина и общего белка при тепловом стрессе, полученная в эксперименте, согласуется с исследованиями Ahmadi F (2012), Abd FG (2014) и Kulak E et al. (2018).

В нашем исследовании уровень глюкозы в плазме самцов-кроликов повышался при воздействии высокой температуры. Также следует отметить, что повышенная температура окружающей среды способствовала увеличению сывороточной активности АСТ, АЛТ и ГГТ. Высокий уровень ГГТ в плазме крови способствует повышению продукции свободных радикалов (Özkan C et al., 2012). Увеличение АСТ, АЛТ, ГГТ в сыворотке крови считают маркером стресса организма (Аһmadi F et al., 2010; Özkan $\mathrm{C}$ et al., 2012).

Наиболее низкая активность сывороточных трансфераз в опытных группах при воздействии высоких температур была у кроликов, получавших УДЧ серебра в дозировке 0,01 мг/кг живой массы. Это согласуется с данными Aleman SL с соавторами (2000), которые изучали биохимические изменения у разных видов животных (обезьян, собак и крыс). Их исследование подтвердило тенденцию увеличения данных ферментов при стрессе.

\section{Выводы.}

Стресс из-за повышенной температуры окружающей среды вызывает негативные изменения морфобиохимических показателей организма, что может привести к снижению продуктивности. Использование суспензии УДЧ серебра в католите в дозе 0,01 мг/кг живой массы способствует улучшению защитных свойств организма и обладает протективным эффектом в отношении теплового стресса.

\section{Исследования выполнены в соответствии с планом НИР на 2019-2021 гг. ФГБНУ ФНЦ БСТ РАН (№ 0761-2019-0006)}

\section{Литература}

1. Ажмулдинов Е.А., Чернышенко Ю.Н., Титов М.Г. Физиологическое состояние и продуктивность животных при воздействии теплового стресса // Вестник Башкирского государственного аграрного университета. 2019. № 3(51). C. 26-31. [Azhmuldinov E, Chernyshenko Y, Titov M. Physiological state and productivity of animals under thermal stress. Vestnik Bashkir State Agrarian University. 2019;3(51):26-31. (In Russ)] doi: 10.31563/1684-7628-2019-51-3-26-31 


\section{0 Технология производства, качество продукции и экономика в мясном скотоводстве}

2. Влияние различных стресс-факторов на организм сельскохозяйственных животных (обзор)/ Е.А. Ажмулдинов, М.А. Кизаев, М.Г. Титов, И.А. Бабичева // Животноводство и кормопроизводство. 2018. T. 101. № 2. C. 79-89. [Azhmuldinov EA, Kizaev MA, Titov MG, Babicheva IA. Influence of various stress factors on the organism of farm animals (review). Animal Husbandry and Fodder Production. 2018;101(2):79-89. (In Russ)].

3. Меерсон Ф.3. Адаптация, стресс и профилактика. М.: Наука, 1981. 279 с. [Meerson FZ. Adaptatsiya, stress i profilaktika. Moscow: Nauka; 1981;279 p. (In Russ)].

4. Способ сокращения потерь мясной продукции бычков при воздействии технологических стресс-факторов: пат. 11197 Рос. Федерация / М.Г. Титов, А.В. Харламов, Е.А. Ажмулдинов, М.А. Кизаев, Н.В. Соболева, И.А. Бабичева, В.А. Манина, Б.Г. Рогачев. Заявл. 25.02.2019; опубл. 15.01.2020, Бюл. № 2. [Titov MG, Kharlamov AV, Azhmuldinov EA, Kizaev MA, Soboleva NV, Babicheva IA, Manina VA, Rogachev BG. Method for reducing losses of meat products of bull-calves under action of technological stress factors: pat. 2711197 Ros. Federatsiya. Zayavl. 25.02.19; opubl. 15.01.2020, Byul. № 2. (In Russ)].

5. Стабилизатор водного раствора и водосодержащего сырья с самопроизвольно изменяющимися окислительно-восстановительными свойствами: пат. 2234945 Рос. Федерация / В.М. Дворников. Заявл. 15.10.02; опубл. 27.08.04, Бюл. № 24. [Dvornikov VM. Stabilizator vodnogo rastvora i vodosoderzhashchego syr'ya s samoproizvol'no izmenyayushchimisya okislitel'no-vosstanovitel'nymi svoistvami: pat. 2234945 Ros. Federatsiya. Zayavl. 15.10.02; opubl. 27.08.04, Byul. № 24. (In Russ)].

6. Частицы серебра: характеристика и применение в животноводстве silver nanoparticles: characterization and application / Е.А. Ажмулдинов, М.А. Кизаев, М.Г. Титов, Н.В. Соболева, И.А. Бабичева // Ветеринарный врач. 2020. № 1. C. 14-22. [Azhmuldinov EA, Kizaev MA, Titov MG, Soboleva NV, Babicheva IA. Silver nanoparticles: characteristic and application in animal husbandry. The Veterinarian. 2020;1:14-22. (In Russ)]. doi: 10.33632/1998-698X.2020-1-14-22

7. Abd FG. Silver nanoparticles effect on some immunological parameters in rabbits. IOSR J. Pharm. Biol. Sci. 2014;9(6):10-12. doi: 10.9790/3008-09611012

8. Abou El-Nour KMM, Eftaiha A, Al-Warthan A, Ammar RAA. Synthesis and applications of silver nanoparticles. Arab. J. Chem. 2010;3(3):135-140. doi: https://doi.org/10.1016/j.arabjc.2010.04.008

9. Ahmadi F. Impact of different levels of silver nanoparticles (Ag-NPs) on performance, oxidative enzymes and blood parameters in broiler chicks. Pak. Vet. J. 2012;26(3):325-328.

10.Ahmadi F, Kurdistan AH. The impact of silver nano particles on growth performance, lymphoid organs and oxidative stress indicators in broiler chicks. Glob. Veterinary. 2010;5(6):366-370.

11.Aklakur Md, Rather AM, Kumar N. Nanodelivery: an emerging avenue for Nutraceuticals and drug delivery. Crit Rev Food Sci Nutr. 2016;56(14):2352-2361. doi: https://doi.org/10.1080/10408398.2013.839543

12.Aleman CL, Noa M, Mas R, Rodeiro I, Mesa R, Menendez R, Gamez R, Hernandez C. Reference data for the principal physiological indicators in three species of laboratory animals. Laboratory Animals. 2000;34:379-385. doi: 10.1258/002367700780387741

13.Al-Sagheer AA, Daader AH, Gabr HA, AbdEl-Moniem EA. Palliative effects of extra virgin olive oil, gallic acid, and lemongrass oil dietary supplementation on growth performance, digestibility, carcass traits, and antioxidant status of heat-stressed growing New Zealand White rabbits. Environ. Sci. Pollut. Res. 2017;24:6807-6818. doi: 10.1007/s11356-017-8396-8

14.Fathi M, Abdelsalam M, Al-Homidan I, Ebeid T, El-Zarei M, Abou-Emera O. Effect of probiotic supplementation and genotype on growth performance, carcass traits, hematological parameters and immunity of growing rabbits under hot environmental conditions. Anim. Sci. J. 2017;88(10):1644-1650. doi: $10.1111 /$ asj.12811

15. Fondevila M. Potential use of silver nanoparticles as an additive in animal feeding. Silver nanoparticles. Perez DP, editor. IntechOpen; 2010:325-334. doi: 10.5772/8509

16.Kulak E, Ognik K, Stępniowska A, Sembratowicz I. The effect of administration of silver nanoparticles on silver accumulation in tissues and immune and antioxidant status of chickens. J. Anim. Feed Sci. 2018;27:44-54. doi: https://doi.org/10.22358/jafs/84978/2018 
17.Marai IFM, Haeeb AAM, Gad AE. Biological functions in young pregnant rabbit does as affected by heat stress and lighting regime under subtropical conditions of Egypt. Trop. Subtrop. Agroecosyst. 2007;7:165-176.

18. Ognik K, Cholewińska E, Czech A, Kozłowski K, Wlazło L, Nowakowicz-Dębek B, Szlązak R, Tutaj K. Effect of silver nanoparticles on the immune, redox, and lipid status of chicken blood. Czech J. Anim. Sci. 2016;61:450-461. doi: 10.17221/80/2015-CJAS

19. Özkan C, Kaya A, Akgül Y. Normal values of haematological and some biochemical parameters in serum and urine of New Zealand rabbits. World Rabbit Sci. 2012;20(4):253-259. doi: $10.4995 /$ wrs. 2012.1229

20.Raheem HQ. Study effect of silver nanoparticles on some blood parameters in rabbits. Biochem. Cell. Arch. 2018;18(1):267-269.

21. Saini P, Saha SK, Roy P, Chowdhury P, Sinha Babu SP. Evidence of reactive oxygen species (ROS) mediated apoptosis in Setaria cervi induced by green silver nanoparticles from Acacia auriculiformis at a very low dose. Exp. Parasitol. 2016;160:39-48. doi: https://doi.org/10.1016/j.exppara.2015.11.004

22. Sarhan OM, Husain RM. Effects of intraperitoneally injected silver nanoparticles on histological structures and blood parameters in the albino rat. Int J Nanomed. 2014;9(1):1505-1517. doi: https://doi.org/10.2147/IJN.S56729

23. Sizova E. Miroshnikov S, Lebedev S, Usha B, Shabunin S. Use of nanoscale metals in poultry diet as a mineral feed additive. Animal Nutrition. 2020;6(2):185-191. doi: https://doi.org/10.1016/j.aninu.2019.11.007

\section{References}

1. Azhmuldinov E, Chernyshenko Y, Titov M. Physiological state and productivity of animals under thermal stress. Vestnik Bashkir State Agrarian University. 2019;3(51):26-31. doi: 10.31563/1684-7628-2019-51-3-26-31

2. Azhmuldinov EA, Kizaev MA, Titov MG, Babicheva IA. Influence of various stress factors on the organism of farm animals (review). Animal Husbandry and Fodder Production. 2018;101(2).79-89.

3. Meerson FZ. Adaptation, stress and preventive measures. Moscow: Nauka. 1981;279 p.

4. Titov MG, Kharlamov AV, Azhmuldinov EA, Kizaev MA, Soboleva NV, Babicheva IA, Manina VA, Rogachev BG. Method for reducing losses of meat products of bull-calves under action of technological stress factors: pat. 2711197 Ros. Federatsiya. Zayavl. 25.02.19; opubl. 15.01.2020, Byul. № 2 .

5. Dvornikov VM. The stabilizer of an aqueous solution and water-containing raw materials with spontaneously changing redox properties: Pat. 2234945 Russian Federation. Application 15.10.02; publ. 27.08.04, Bull. Number 24.

6. Azhmuldinov EA, Kizaev MA, Titov MG, Soboleva NV, Babicheva IA. Silver nanoparticles: characteristic and application in animal husbandry. The Veterinarian. 2020;1:1422. doi: 10.33632/1998-698X.2020-1-14-22

7. Abd FG. Silver nanoparticles effect on some immunological parameters in rabbits. IOSR J. Pharm. Biol. Sci. 2014;9(6):10-12. doi: 10.9790/3008-09611012

8. Abou El-Nour KMM, Eftaiha A, Al-Warthan A, Ammar RAA. Synthesis and applications of silver nanoparticles. Arab. J. Chem. 2010;3(3):135-140. doi: https://doi.org/10.1016/j.arabjc.2010.04.008.

9. Ahmadi F. Impact of different levels of silver nanoparticles (Ag-NPs) on performance, oxidative enzymes and blood parameters in broiler chicks. Pak. Vet. J. 2012;26(3):325-328.

10. Ahmadi F, Kurdistan AH. The impact of silver nano particles on growth performance, lymphoid organs and oxidative stress indicators in broiler chicks. Glob. Veterinary. 2010;5(6):366-370.

11.Aklakur Md, Rather AM, Kumar N. Nanodelivery: an emerging avenue for Nutraceuticals and drug delivery. Crit Rev Food Sci Nutr. 2016;56(14):2352-2361. doi: https://doi.org/10.1080/10408398.2013.839543

12.Aleman CL, Noa M, Mas R, Rodeiro I, Mesa R, Menendez R, Gamez R, Hernandez C. Reference data for the principal physiological indicators in three species of laboratory animals. Laboratory Animals. 2000;34:379-385. doi: 10.1258/002367700780387741

13.Al-Sagheer AA, Daader AH, Gabr HA, AbdEl-Moniem EA. Palliative effects of extra virgin olive oil, gallic acid, and lemongrass oil dietary supplementation on growth performance, digestibility, car- 


\section{2 Технология производства, качество продукции и экономика в мясном скотоводстве}

cass traits, and antioxidant status of heat-stressed growing New Zealand White rabbits. Environ. Sci. Pollut. Res. 2017;24:6807-6818. doi: 10.1007/s11356-017-8396-8

14.Fathi M, Abdelsalam M, Al-Homidan I, Ebeid T, El-Zarei M, Abou-Emera O. Effect of probiotic supplementation and genotype on growth performance, carcass traits, hematological parameters and immunity of growing rabbits under hot environmental conditions. Anim. Sci. J. 2017;88(10):1644-1650. doi: $10.1111 /$ asj.12811

15.Fondevila M. Potential use of silver nanoparticles as an additive in animal feeding. Silver nanoparticles. Perez DP, editor. IntechOpen; 2010:325-334 doi: 10.5772/8509

16.Kulak E, Ognik K, Stępniowska A, Sembratowicz I. The effect of administration of silver nanoparticles on silver accumulation in tissues and immune and antioxidant status of chickens. J. Anim. Feed Sci. 2018;27:44-54. doi: https://doi.org/10.22358/jafs/84978/2018

17.Marai IFM, Haeeb AAM, Gad AE. Biological functions in young pregnant rabbit does as affected by heat stress and lighting regime under subtropical conditions of Egypt. Trop. Subtrop. Agroecosyst. 2007;7:165-176.

18. Ognik K, Cholewińska E, Czech A, Kozłowski K, Wlazło L, Nowakowicz-Dębek B, Szlązak R, Tutaj K. Effect of silver nanoparticles on the immune, redox, and lipid status of chicken blood. Czech J. Anim. Sci. 2016;61:450-461. doi: 10.17221/80/2015-CJAS

19. Özkan C, Kaya A, Akgül Y. Normal values of haematological and some biochemical parameters in serum and urine of New Zealand rabbits. World Rabbit Sci. 2012;20(4):253259. doi: $10.4995 /$ wrs. 2012.1229

20. Raheem HQ. Study effect of silver nanoparticles on some blood parameters in rabbits. Biochem. Cell. Arch. 2018;18(1):267-269.

21. Saini P, Saha SK, Roy P, Chowdhury P, Sinha Babu SP. Evidence of reactive oxygen species (ROS) mediated apoptosis in Setaria cervi induced by green silver nanoparticles from Acacia auriculiformis at a very low dose. Exp. Parasitol. 2016;160:39-48. doi: https://doi.org/10.1016/j.exppara.2015.11.004

22. Sarhan OM, Husain RM. Effects of intraperitoneally injected silver nanoparticles on histological structures and blood parameters in the albino rat. Int $J$ Nanomed. 2014;9(1):15051517. doi: https://doi.org/10.2147/IJN.S56729

23. Sizova E. Miroshnikov S, Lebedev S, Usha B, Shabunin S. Use of nanoscale metals in poultry diet as a mineral feed additive. Animal Nutrition. 2020;6(2):185-191. doi: https://doi.org/10.1016/j.aninu.2019.11.007

Ажмулдинов Елемес Ажмулдинович, доктор сельскохозяйственных наук, профессор, главный научный сотрудник отдела технологии мясного скотоводства и производства говядины, Федеральный научный центр биологических систем и агротехнологий Российской академии наук, 460000, г. Оренбург, ул. 9 Января, 29, тел.: 8(3532)30-81-78

Титов Максим Геннадьевич, кандидат сельскохозяйственных наук, старший научный сотрудник отдела технологии мясного скотоводства и производства говядины, Федеральный научный центр биологических систем и агротехнологий Российской академии наук, 460000, г. Оренбург, ул. 9 Января, 29, тел.: 8(3532)30-81-78, e-mail: titow.ru@mail.ru

Кизаев Михаил Анатольевич, кандидат сельскохозяйственных наук, учёный секретарь, Федеральный научный центр биологических систем и агротехнологий Российской академии наук, 460000, г. Оренбург, ул. 9 Января, 29, тел.: 8(3532)30-81-73; e-mail: kma.or@mail.ru

Холодилина Татьяна Николаевна, кандидат сельскохозяйственных наук, заведующий Испытательным центром ЦКП, Федеральный научный центр биологических систем и агротехнологий Российской академии наук, 460000, г. Оренбург, ул. 9 Января, 29, тел.: 8(3532)30-81-77, e-mail: icvniims@mail.ru

Поступила в редакцию 2 сентября 2020 г.; принята после решения редколлегии 14 сентября 2020 г.; опубликована 30 сентября 2020 г./ Received: 2 September 2020; Accepted: 14 September 2020;

Published: 30 September 2020 